\title{
FLOW INJECTION SPECTROPHOTOMETRIC DETERMINATION OF FLUOXETINE IN BULK AND IN PHARMACEUTICAL PREPARATIONS
}

\author{
JASMIN SHAH*, M.RASUL JAN AND FOZIA REHMAN \\ Institute of chemical sciences, university of Peshawar, N.W.F.P., Pakistan \\ (Received: November 9, 2007 - Accepted: April 10, 2008)
}

\begin{abstract}
Sensitive and reproducible flow injection spectrophotometric method for determination of fluoxetine in pharmaceutical preparation has been developed. The method is based on base hydrolysis of the drug. The hydrolyzed product methylamine is reacted with sodium nitroprusside. The absorbance of the resulting colored product was measured spectrophtometrically at $510 \mathrm{~nm}$ using flow injection method. The method showed a linear range $0.5-25 \mathrm{mg} / \mathrm{L}$ with a molar absorptivity of $2.19 \times 10^{4}$. The \% recovery for determination of flouxitine in formulations was found to be $99.7 \pm 0.18-99.4 \pm 0.22$. The limit of detection and quantification was calculated and found $0.15 \pm 0.01 \mathrm{mg} / \mathrm{L}$ and $0.29 \pm 0.03 \mathrm{mg} / \mathrm{L}$ respectively. The proposed method was successfully applied to the pharmaceutical preparationscapsules and tablets.
\end{abstract}

Key words: Fluoxetine, hydrolysis, flow injection, spectrophotometric

\section{INTRODUCTION}

Fluoxetine, (3RS) - N- methyl -3- phenyl -3-[(4-(trifluoromethyl) phenoxy)] propane -1- amine, (Fig-1) is a bicyclic derivative of phenyl propylamine, widely used as antidepressant. Fluoxetine enhances serotoninergic neurotransmission process, through selective inhibition of neuronal reuptake of serotonin in presynaptic neurons. Fluoxetine is extensively metabolized by Ndemethylation in liver into its active metabolite norfluoxetine ${ }^{1}$.

Reported methods for the determination of fluoxetine are mainly based on high performance liquid chromatography ${ }^{2-9}$ and Gas chromatography ${ }^{10-}$ 12. Spectrofluoremetric methods have also used by few researchers ${ }^{13-15}$. The reported spectrophotomtric methods for fluoxetine are based on charge transfer complexes with chloranil, 2,3 dichloro-5,6-dicyanoquinone ${ }^{16}$, ion pair complexes with methyl orange and thymol blue ${ }^{17}$, pyrocatechol violet ${ }^{18}$, bromothymol blue, bromocresol green and bromophenol blue ${ }^{19}$, ion association compounds with erichrome cyanine $\mathrm{R}$ and chrome azurol $\mathrm{S}^{20,21}$ and colored vinylamino substituted quinones with haloquinones in the presence of acetaldehyde ${ }^{22}$. Most of these spectrophotometric methods based on liquidliquid extraction before measurement of absorption.

The flow injection methods have also been reported for determination of flouxetine using square wave adsorptive voltammetric method ${ }^{23}$ and spectrophotometric method based on competitive complexation reaction with phenolphthalein- $\beta$-cyclodextrin inclusion complex ${ }^{24}$. In the present work simple, direct and sensitive flow injection spectrophotometric method has been proposed based on rapid hydrolysis of fluoxtine with sodium ethoxide, which results in the production of methylamine. Sodium nitroprusside a well-known reagent has been used for the determination of methylamine ${ }^{25}$. Methylamine is reacted with sodium nitroprusside in the presence of acetone and resulted in a colored product with maximum absorption at $510 \mathrm{~nm}$.

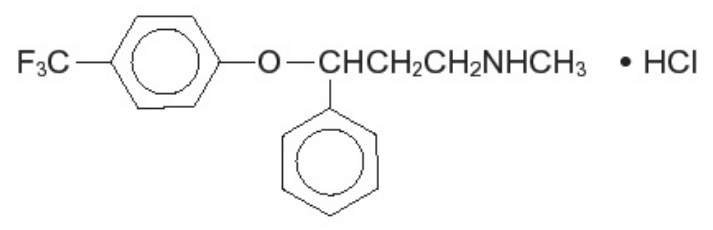

Fig: 1 Fluoxetine structure

\section{EXPERIMENTAL}

\section{Apparatus}

1- A UV/Vis spectrophotometer (UNICO UV-2100 United Products and Instruments Inc., Dayton, N.J U.S.A), peristaltic pump, PTFE tubing (i.d. $1.19 \mathrm{~mm}$, Becton Dickson, USA), silicon tube (i.d.1.71mm), V-450 6 port injection valve (Upchurch Scientific Inc, USA), Digital Analytical Balance (Sartorius handy H51, Germany). The flow- injection system is shown in Fig 2 .

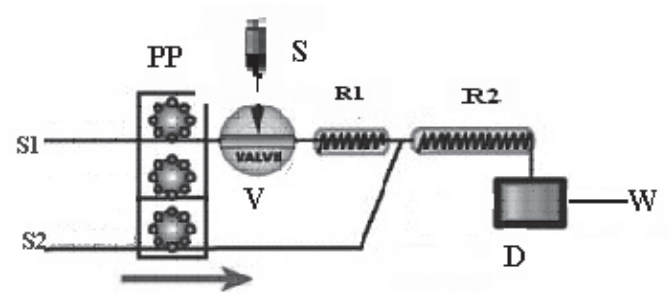

Fig. 2. Schematic diagram of the FI-manifold. (S1) sodium ethoxide solution, (S2) sodium

nitroprusside solution, (R1) hydrolysis coil, (R2) coupling coil, (pp) peristaltic pump, (S) sample injected, (V) valve, (W) Waste, (D) detector.

Reagents

All reagents used were of analytical reagent grade purity. Sodium nitroprusside $(\mathrm{BDH})$, Sodium metal $(\mathrm{BDH})$, Acetone (Merck) and double distilled ethanol were used during this work. Standard reference material was purchased from Cadila Pharma Pvt Ltd India (manufacturer). Dosage forms fluoxetine were purchased from local market. The solutions were prepared in distilled water.

1. Sodium nitroprusside solution $(5 \%)$ was prepared by dissolving $5 \mathrm{~g}$ sodium nitroprusside in distilled water in a $100 \mathrm{ml}$ volumetric flask.

2. Sodium ethoxide solution $(10 \%)$ was prepared by dissolving $10 \mathrm{~g}$ of sodium metal in ethanol in a $100 \mathrm{ml}$ volumetric flask.

\section{Standard Fluoxetine solution}

Fluoxetine solution $(1000 \mathrm{mg} / \mathrm{L})$ was prepared by dissolving $0.1 \mathrm{~g}$ of standard in distilled water and diluted to $100 \mathrm{~mL}$. Through step wise dilution 100 and $10 \mathrm{mg} / \mathrm{L}$ and $1 \mathrm{mg} / \mathrm{L}$ solution were prepared with distilled water. Similarly, working standards in the range of 10 to $0.02 \mathrm{mg} / \mathrm{L}$ were prepared from the stock solution by dilution.

\section{Recommended Procedure}

A flow through spectrophotometric cell was used in a double channel flow injection system for online hydrolysis of fluoxetine. Sodium ethoxide solution $(0.9 \%)$ was continuously flowing in stream S1 and in S2 $0.4 \%$ sodium nitroprusside solution in acetone as reagent was propelled through the cell, by means of peristaltic pump and PTFE tubing, at a flow rate of $1.5 \mathrm{ml} / \mathrm{min}$. Aliquots of the fluoxetine sample solution were injected into the sodium ethoxide flow stream through a 6 port injector valve and fluoxetine was hydrolyzed in a reactor coil R1. The hydrolyzed fluoxetine further reacted with sodium nitroprusside reagent and coupling reaction completed in reaction coil R2 before reaching the flow through spectrophotometric cell. Calibration graph was prepared by plotting the absorbance versus fluoxetine concentration.

Determination of Fluoxetine

The average capsule and tablet weight was calculated from the content of 5 capsules as well as tablets. A portion of the powder form of capsule and tablet, equivalent to $20 \mathrm{mg}$ of fluoxetine, was accurately weighed. The samples were dissolved in distilled water and filtered to separate any suspended particles. 
The filtrate was diluted further to $100 \mathrm{~mL}$. Appropriate aliquots of the solution obtained were treated according to the procedure.

\section{RESULTS AND DISCUSSION}

Fluoxetine has a primary aliphatic amine group (the proposed method is based on hydrolysis of fluoxetine into methylamine). When methylamine reacts with sodium nitroprusside in the presence of acetone, red colored product is formed. The same procedure is applied for determination of fluoxetine in pharmaceutical preparations. The methylamine librated from fluoxetine on alkaline hydrolysis and followed by reaction with sodium nitroprusside in the presence of acetone to form a red colored product.

The absorption spectrum of the red colored product formed has an absorption maximum at $510 \mathrm{~nm}$ against the reagent blank using batch and FI methods (Fig 3).

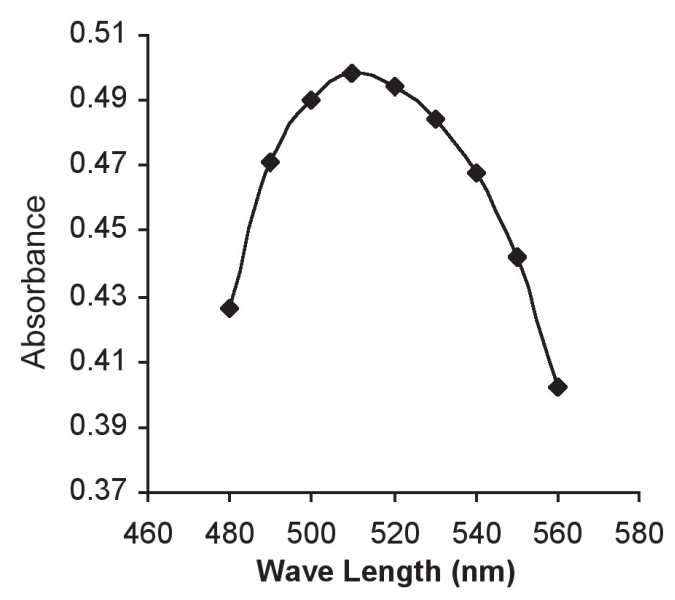

Fig. 3 Absorption spectra of red product of fluoxetine $(10 \mathrm{mg} / \mathrm{L})$ With sodium nitroprusside reagent.

Preliminary experiments under continuous flow condition were carried out to test the flow injection system and the approximate ranges of the tested parameters. The design of multichannel flow injection system selected for analysis is shown in Fig 2. For flow injection analysis different chemical and physical variables like reagents concentrations, reactor coil length, flow rate of reagent and injection volume were optimized. Fluoxetine was hydrolyzed with sodium ethoxide in a continuous flow of sodium ethoxide solution and the concentration was adjusted in the range of $0.2-1.2 \%$. Maximum hydrolysis was observed at $0.9 \%$ concentration of sodium ethoxide at room temperature (Fig 4). Above this concentration a decrease in absorbance was observed.

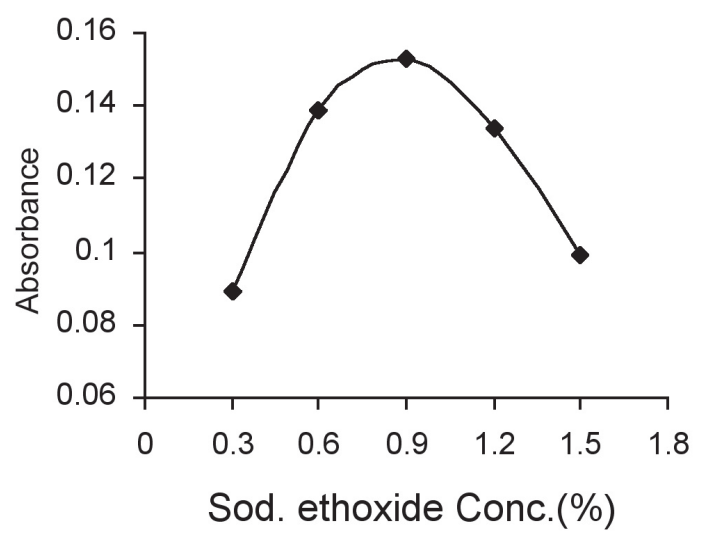

Fig. 4. Effect of sodium ethoxide on hydrolysis of Fluoxetine

For maximum formation of red colored product, the concentration of sodium nitroprusside was optimized in the range of $0.1-0.7 \%$ and it was found that maximum absorption obtained at $0.4 \%$ concentration of sodium nitroprusside (Fig 5). The red product is not stable in aqueous media therefore; polar organic solvents miscible with aqueous media were analyzed. Acetone gave good stability of the red product among different organic solvents. Volume of acetone was optimized (Fig 6) and maximum stability was found at $4 \mathrm{~mL}$ of acetone.

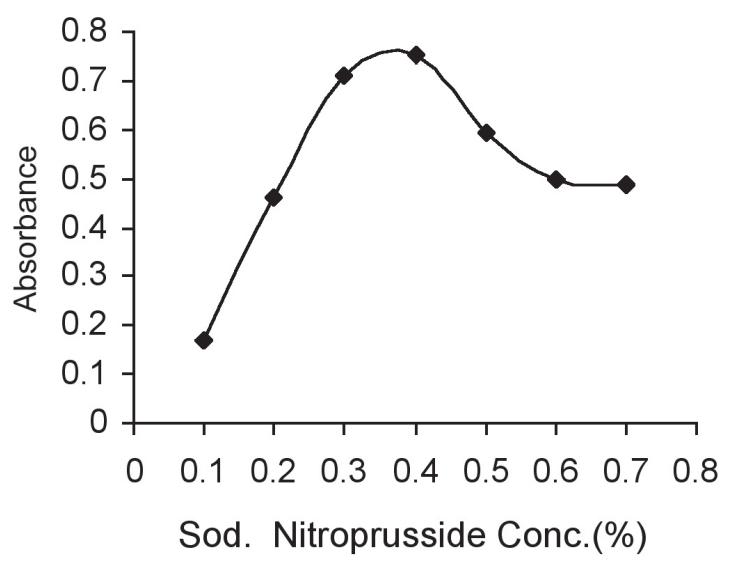

Fig. 5 Effect of sodium nitroprusside concentration on red product formation

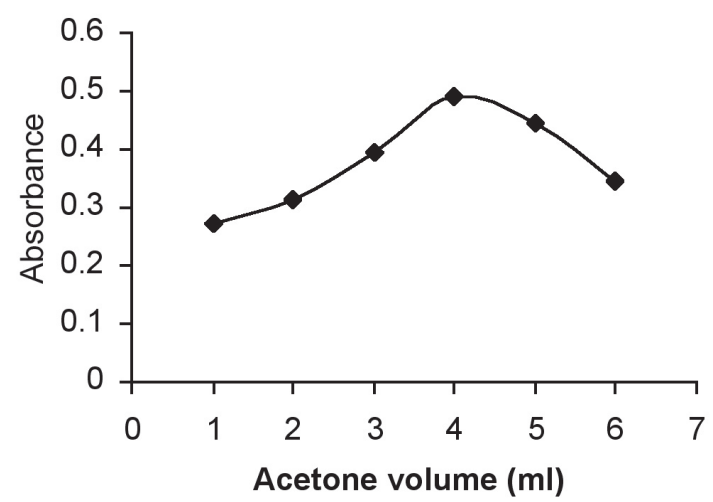

Fig. 6 Effect of acetone volume on stability of red product.

The drug sample was injected into sodium nitroprusside/acetone reagent stream. The influence of reactor coil length was studied in the range of $30-150$ $\mathrm{cm}$ (Fig 7). As can be seen from figure that maximum absorbance was obtained at $90 \mathrm{~cm}$ reactor coil length. The effect of flow rate on absorbance was studied in the range of $1.5-5 \mathrm{~mL} / \mathrm{min}$ in both $\mathrm{R} 1$ and $\mathrm{R} 2$ reactor coils. Fig 8 shows maximum absorbance at $1.5 \mathrm{~mL} / \mathrm{min}$ flow rate of reagent. Above this rate a decrease in absorbance was observed. The volume of sample injected was also changed and a sample loop of $1 \mathrm{~mL}$ was selected to maintain a good sampling rate and high absorbance. The flow rate selected provides a sampling frequency of 60 samples per hour. 


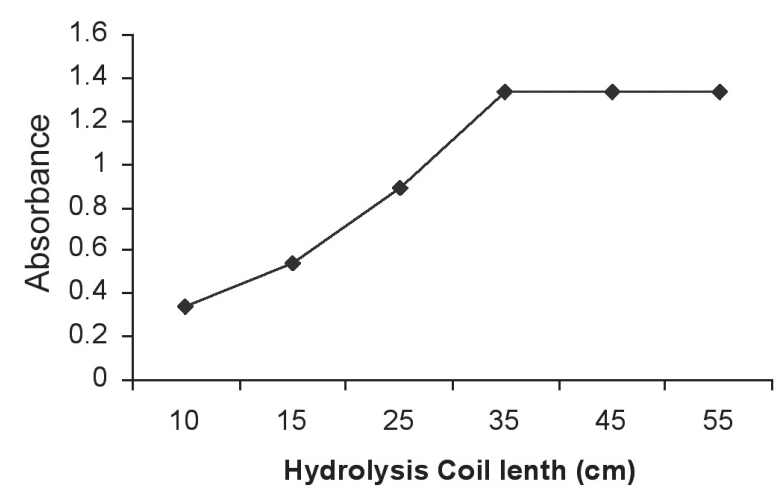

Fig.7 Effect of reactor coil length R1 on the online hydrolysis of Fluoxetine.

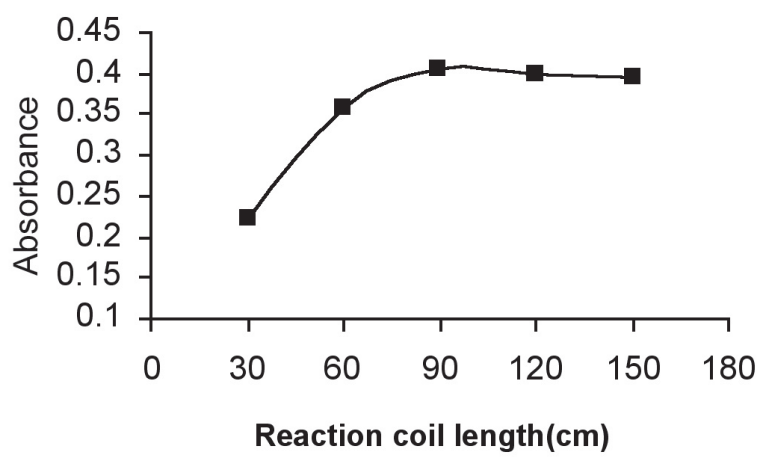

Fig 8. Effect of reactor coil length (R2) on reaction product.

\section{Analytical characteristics}

The proposed method was tested for linearity, precision and sensitivity under the optimized conditions, a linear relationship between fluoxetine concentration and absorption intensity was obtained over the range of $0.5-25$ $\mathrm{mg} / \mathrm{L}$ with a correlation coefficient $\left(\mathrm{r}^{2}\right)$ of 0.9979 . The limit of detection $(3 \delta)$

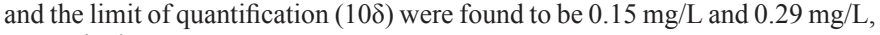
respectively.

Table 1: Spectral Characteristics for Spectrophotometric Determination of Fluoxetine

\begin{tabular}{|l|c|}
\hline \multicolumn{1}{|c|}{ Characteristics } & Value \\
\hline Wave length, $\lambda(\mathrm{nm})$ & 510 \\
\hline Linear range $(\mathrm{mg} / \mathrm{L})$ & $0.5-25$ \\
\hline Slope $(\mathrm{mg} / \mathrm{L})$ & 0.187 \\
\hline Correlation coefficient $\left(\mathrm{r}^{2}\right)$ & 0.9979 \\
\hline Relative standard deviation $(\mathrm{RSD})$ & 7.97 \\
\hline Limit of detection $(\mathrm{mg} / \mathrm{L})$ & $0.15 \pm 0.01$ \\
\hline Limit of quantification $(\mathrm{mg} / \mathrm{L})$ & $0.29 \pm 0.03$ \\
\hline Molar Absorptivity $\left(\mathrm{L} \mathrm{mol}^{-1} \mathrm{~cm}^{-1}\right)$ & $2.19 \times 10^{4}$ \\
\hline
\end{tabular}

\section{Applications}

The validity of the method was confirmed by applying the standard addition technique to the different pharmaceutical formulations of fluoxetine. For recovery studies, known quantities of pure fluoxetine in the concentration range $5-12 \mathrm{mg} / \mathrm{L}$ were mixed with known amount of pre-analyzed formulations $(5 \mathrm{mg} / \mathrm{L})$ and the mixtures were analyzed by the proposed method. The total amount of the fluoxetine was then determined and the amount of the added fluoxetine was calculated by difference. The quantitative average percent recoveries obtained were $99.4-99.7 \%$ (Table 2) indicate good accuracy and applicability of the proposed method for the analysis of dosage form.

Table 2. Recoveries of Fluoxetine from pharmaceuticals formulations

\begin{tabular}{|l|c|c|c|c|}
\hline \multicolumn{1}{|c|}{ Sample } & $\begin{array}{c}\text { Taken } \\
\mathrm{mg} / \mathrm{mL}\end{array}$ & $\begin{array}{c}\text { Added } \\
\mathrm{mg} / \mathrm{mL}\end{array}$ & $\begin{array}{c}\text { Found } \\
\mathrm{mg} / \mathrm{mL}\end{array}$ & $\%$ Recovery \\
\hline & & 0 & 4.98 & $99.6 \pm 0.24$ \\
Flotin & 5 & 5 & 9.94 & $99.4 \pm 0.18$ \\
& & 8 & 12.96 & $99.5 \pm 0.12$ \\
& & 12 & 16.92 & $99.5 \pm 0.20$ \\
\hline & & 0 & 4.97 & $99.4 \pm 0.19$ \\
Floxitol & 5 & 5 & 9.94 & $99.4 \pm 0.22$ \\
& & 10 & 14.96 & $99.7 \pm 0.18$ \\
& & 12 & 16.93 & $99.6 \pm 0.25$ \\
\hline
\end{tabular}

The interferences effects of excipients were tested for the determination of fluoxetine. It was found that starch, glucose, sucrose, talc, lactose, sorbitol, dextrose and magnesium stearate did not interfere in the determination of fluoxetine at the level found in dosage forms.

The proposed method was applied successfully to the determination of fluoxetine in two commercial formulations of tablets containing $20 \mathrm{mg}$ of fluoxetine per unit label value. The sample solutions were prepared and analyzed by the recommended flow injection spectrophotometric method under optimum experimental conditions. The fluoxetine contents in each sample were determined and the results (Table 3 ) obtained were in good agreement with that of the label value. The results were compared statistically by student t-test at $95 \%$ confidence level indicating that there is no significant difference between the proposed method and label value.

Table 3. Determination of Fluoxetine in pharmaceutical samples.

\begin{tabular}{|c|c|c|}
\hline Sample & $\begin{array}{c}\text { Calculated amount on } \\
\text { FIA (mg/ tablet) }\end{array}$ & $\begin{array}{c}\text { Labeled amount }(\mathrm{mg} / \\
\text { tablet })\end{array}$ \\
\hline Flotin & $\begin{array}{c}21.2 \pm 0.12 \\
\mathrm{t}=2.028(2.778)\end{array}$ & 20.0 \\
\hline Floxitol & $\begin{array}{c}21.0 \pm 0.05 \\
\mathrm{t}=2.182(3.135)\end{array}$ & 20.0 \\
\hline
\end{tabular}

\section{CONCLUSION}

The red product produced by reaction of fluoxetine after online hydrolysis and sodium nitroprusside is stable in aqueous media with a small concentration of acetone and has spectrophotometric characteristics suitable for application to the spectrophotometric determination of the drug by FI technique.

The FI spectrophotometric method proposed for the determination of fluoxetine in pure and pharmaceutical forms has the advantages of simplicity, speed, accuracy and use of inexpensive equipment.

\section{REFERENCES}

1. F. Gevirtz, K. Way, C.H. Young, T. Coleman, K. Gregor, J. Manage. Care Pharm. 5, 138, (1999).

2. J.H. Nichols, J.R. Charlson, G.M. Lawson, Clin. Chem. 40, 1312, (1994).

3. H. Kirchherr, W.N. Kuhn-Velten, J. Chromatogr. B 843, 100, (2006).

4. J.C. Rodrigues, A.J. Neto, C. Fernandes, C. Alves, A.S. Contadori, F.M. Lancas, J. Chromatogr. A. 1105, 208, (2006).

5. I. Kovacevic, M. Pokrajac, B. Miljkovic, D. Jovanovic, M. Prostran, J. Chromatogr. B Analyt. Technol. Biomed. Life Sci. 830, 372, (2006).

6. A. Llerena, P. Dorado, R. Berecz, A. Gonzalez, M.J. Norberto, A. de la Rubia, M. Caceres, J. Chromatogr. B, 783, 25, (2003) .

7. W.F. Smyth, J.C. Leslie, S. McClean, B. Hannigan, H.P. McKenna, B. Doherty, C. Joyce, E. O'Kane, Rapid. Commun. Mass Spectrom. 20, 1637, (2006).

8. M.J. Gomez, M. Petrovic, A.R. Fernandez-Alba, D. Barcelo, J. Chromatogr. A. 1114, 224, (2006).

9. F.L. Sauvage, J.M. Gaulier, G. Lachatre, P. Marquet, Ther. Drug Monit. 28, 123, (2006). 
10. J.J.B. Nevado, M.J.V. Llerena, C.G. Cabanillas, V.R. Robledo, S. Buitrago, J. Sep. Sci. 29, 103, (2006).

11. S.M. Wille, K.E. Maudens, C.H. Van Peteghem, W.E Lambert, J. Chromatogr. A. 1098, 19, (2005).

12. J.J.B. Nevado, M.J.V. Llerena, A.M.C. Salcedo, E.A. Nuevo, J. Pharm. Biomed. Anal. 38, 52, (2005)

13. J.J. Berzas, A. Alanon, J.A. Lazaro, Talanta 58, 301, (2002).

14. M.I.Gonzalez-Martin, C.Gonzalez-Perez, Anal. Lett. 30, 2493, (1997).

15. S. Atmaca, Pharmazie 50, 300, (1995).

16. L.I. Bebawy, N. El-Kousy, J.K. Suddik, M. Shokry, J. Pharm. Biomed. Anal. 21, 133, (1999).

17. A. H. Prabhakar, V.B. Patel, R. Giridhar, J. Pharm. Biomed. Anal. 20, 427, (1999)
18. B. Starczewska, A. Jasinska, B. Bialous, Pharmazie. 58, 245, (2003).

19. A. Onal, S.E. Kepekci, S.M. Cetin, S. Erturk, J.A.O.A.C. Int. 89, 966, (2006).

20. B. Starczewska, K. Mielech, E. Kleszczewska, Psychiatr. Pol. 36, 603, (2002).

21. B. Starczewska, K. Mielech, J. Pharm. Biomed. Anal. 23, 243, (2000).

22. I.A. Darwish, J.A.O.A.C. Int. 88, 38, (2005).

23. H.P.A. Nouws, C. Delerue-Matos, A.A.Barros, J.A.Rodrigues, A. SantosSilva, F. Borges, Anal. Lett., 40, 1131, (2007).

24. A.Afkhami, T.Madrakian, L. Khalafi, Chem. Pharm. Bull., 54, 1642, (2006).

25. F. Feigl, Spot Tests in Organic Analysis, $6^{\text {th }}$ Ed., Elsevier Publishing Company, Netherlands, 1960, pp.283. 